\title{
A PARRESÍA NO CANCIONEIRO DE VIOLETA PARRA CANTADO POR MERCEDES SOSA EM HOMENAJE A VIOLETA PARRA
}

Jorge Alves Santana ${ }^{92}$

RESUMO: Mercedes Sosa, cantora argentina e ativista político-cultural, presta uma homenagem à artista chilena, e também grande ativista, Violeta Parra, em seu disco Homenaje a Violeta Parra, em 1971. Ambas pertencem, respectivamente, aos movimentos culturais denominados por Novo Cancioneiro e Movimento da Nova Canção Chilena. Movimentos estes perspectivados por um vigoroso multiculturalismo questionador das desigualdades sociais, das produções culturais de massa, dos regimes políticos ditatoriais, entre outras causas e temas. Sobretudo, são movimentos movidos pela vontade da ação dialógica entre os povos latinoamericanos. Desse cancioneiro, acompanharemos as canções Defensa de Violeta Parra (Nicanor Parra), Gracias a la vida, Me gustan los estudiantes, Los hambrientos piden pan [o La carta], e Los pueblos americanos. Tais canções, escritas por Violeta Parra e interpretadas por Mercedes Sosa, demonstramnos como as complexas mobilidades psicossociais de tais ativistas podem dinamizar o contexto da parresía (o jogo político agonístico no qual se tenta convencer sobre o valor necessário de certa verdade) para a construção de um socius pragmaticamente crítico e igualitário. Quadro socioestético este que valoriza mais a dimensão coletiva da produtividade cultural, que aquela dimensão das individualidades de tais artistas ativistas.

Palavras-Chave: Violeta Parra; Mercedes Sosa; Cancioneiro Latinoamericano; Parresía

ABSTRACT: Mercedes Sosa, Argentine singer, political and cultural activist, pays tribute to the Chilean artist and also activist Violeta Parra, in her record Homenaje a Violeta Parra, 1971. Both belong, respectively, to the cultural movements named Nuevo Cancionero and Nueva Canción Chilena. Movements that were seen by the vigorous perspective of multiculturalism, that questioned social inequality, mass production of

\footnotetext{
${ }^{92}$ Professor Associado III da Faculdade de Letras da Universidade Federal de Goiás. Membro Permanente do Programa de Pós-Graduação em Letras e Linguistica da FL/UFG, Pós-Doutor em Estudos Literários e Estudos Culturais pelo PÓS/LIT da UFMG.
} 
culture, dictatorships, among other causes and themes. Mainly these are movements moved by the desire of a dialogic action among Latin Americans. We'll follow the songs Defensa de Violeta Parra (Nicanor Parra), Gracias a la vida, Me gustan los estudiantes, Los hambrientos piden pan lo La carta], and Los pueblos americanos. Such songs, written by Violeta Parra and played by Mercedes Sosa, show us how this intricate psychosocial mobilities can simplify the context of parrhesia (the political game in which a person tries to convince the others of the necessity of certain truth) for the construction of a pragmatically critic and egalitarian socius. A social aesthetics picture that values the collective dimension of the cultural productivity more than the dimension of the artists' individualities.

Keywords: Violeta Parra; Mercedes Sosa; Cancionero Latinoamericano; Parrhesia

Cántame una canción

inolvidable

Una canción que no termine nunca

Una canción no más una canción

Es lo que pido.

Defensa de Violeta. Nicanor Parra. In: Homenaje a Violeta Parra, de Mercedes Sosa, 1971.

Sólo le pido a Dios

Que el dolor no me sea indiferente

Que la reseca muerte no me encuentre

Vacía y sola sin haber hecho lo suficiente.

Sólo de pido a Dios. León Gieco. In: Corazón Americano, de Mercedes Sosa, León Gieco e Milton Nascimento, 1986. 
Y el canto de todos que es mi propio canto

Gracias a la vida, gracias a la vida.

Gracias a la vida. Violeta Parra.

In: Homenaje a Violeta Parra, de Mercedes Sosa, 1971.

\section{Introdução}

Mercedes Sosa lança o álbum de músicas Homenaje a Violeta Parra, no ano de 1971, divulgando parte do cancioneiro composto pelo trabalho de produção e de resgate multicultural dessa ativista político-cultural chilena que é Violeta Parra. Desse álbum, vêm-nos à memória a já clássica canção Gracias a la vida, que é uma canção representativa do paradigma estético ativista de Violeta. Vejamos o que sua última estrofe nos sintetiza sobre um dos lugares de fala mais instigantes de nosso multiculturalismo latinoamericano:

Gracias a la vida que me ha dado tanto

Me ha dado la risa y me ha dado el llanto

Así yo distingo dicha de quebranto

Los dos materiales que forman mi canto

Y el canto de ustedes que es el mismo canto

Y el canto de todos que es mi propio canto

Gracias a la vida, gracias a la vida (SOSA, 1971).

Uma das características marcantes dessa canção é o fato de que o canto proposto pela artista é feito no entrecruzamentos dos cantos coletados, produzidos e vivenciados em uma rede ampla e heterogênea de coexistências. O canto de todos é que forma a base para a produção e necessidade de divulgação e consolidação dos cantares de vários povos que perfazem as cartografias dos povos americanos. Essa natureza coletiva forma o construto histórico ao qual a artista agradece.

O cancioneiro que Mercedes Sosa divulga nesse trabalho também tem a função de demonstrar como funciona o jogo agonístico pela construção de discursos socioestéticos que configuram a luta pelo poder político em nossas sociedades. Assim, ao lado das exposições do folclores 
de povos ex-cêntricos, injustiçados e invisibilizados, a produção artística de Violeta Parra nos instiga a refletir sobre a veridicção de valores, crenças e comportamentos rumo aos dispositivos discursivos que veiculam campos de verdades. Tais campos implicam no que Michel Foucault (2006; 2010; 2011) aponta em relação às tecnologias do conhecimento de si e dos outros, que são compreendidas na ação e reação da parresía. Ou seja, o poder de expressar verdades críticas e deslocadoras do status quo, que a organização social estratificada e excludente de modo usual nos impede.

O movimento da Nova Canção Chilena ${ }^{93}$, da qual Violeta Parra é uma das iniciadoras, e o Novo Cancioneiro, do qual Mercedes Sosa é uma das grandes divulgadoras, funcionam aqui como cartografias para refletirmos sobre um recorte de corpus, do álbum musical acima citado, formado pelas canções Defensa de Violeta Parra (Nicanor Parra), Gracias a la vida, Me gustan los estudiantes, Los hambrientos piden pan [o La carta], e Los pueblos americanos ${ }^{94}$. Tais canções expressam-nos as variadas mobilidades

${ }^{93}$ Sobre o movimento cultural A Nova Canção Chilena, com vinculação sistêmica ao Novo Cancioneiro argentino, Claudio Rolle nos explica: "La Nueva Canción Chilena, corriente artistica surgida en los años sesenta y caracterizada por un replanteamiento del cantar popular acorde a la evolución de la sociedad, se convirtió en una significativa plataforma de apoyo cultural para la campaña presidencial de Salvador Allende en 1970. Más adelante contribuyó activamente en la promoción de las actividades del gobierno de la Unidad Popular generando una producción de temas orientados a crear conciencia politica entre los sectores populares, a replantear la historia del movimiento popular y a destacar las responsabilidades planteadas por la via chilena al socialismo" (ROLLE, 2016). Para mais informações sobre tais movimentos, queira acompanhar MEMÓRIAS DA DITADURA, 2016; PSTU, 2016; RODRÍGUEZ, 2016; BESSA, 2016; e MODELLI, 2016.

${ }^{94}$ Singulares vinculações, além do projeto artístico politizado, unem essas duas artistas, como nos conta Cristian Urbia: "Llamémosle casualidad, coincidencia, destino o designio, lo cierto es que un 4 de octubre despedimos a Mercedes Sosa y un mismo 4 de octubre, hace ya muchos años (1917), el mundo recibe en su cuna a nuestra querida Violeta Parra. La primera, argentina, la segunda chilena o tal vez ambas originarias de la república de "transandinia", como lo proclamaba el grupo Quilapayún en su mítico concierto en Argentina (1983). De ambas podríamos decir muchas cosas. Entregadas por completo a su oficio, traspasan fronteras y llevan la sangre latinoamericana por el mundo; ambas recopilan y cantan, ambas desafian la estética impuesta de los mercados y se atreven y rezongan y reclaman el lugar que siempre debió tener la música folclórica latinoamericana.

Las similitudes son múltiples y se condicen y entrelazan como manos de mujer tejiendo el chaleco de la historia de nuestros pueblos, sus repertorios, versiones en Mercedes, creaciones en Violeta. Siempre prefirieron a la gente antes que el ego artístico tan común en nuestros tiempos; siempre la reflexión a la entretención barata; siempre el festejo comunitario al bullicio comercial. Su canto de madres ahora nos protege y nos sigue indicando el camino del arte y de las luchas que aún persisten en las democracias y necesitan ser reivindicadas.

Sin embargo, sucede una no menos triste que amplia diferencia entre ambas y curiosamente no tiene que ver con ellas. Hoy que lamentamos la ausencia de Mercedes y en donde por otra 
socioestéticas que tais artistas ativistas dinamizam no contexto da parresía, esse jogo discursivo e vivencial que pretende transformar, apesar de seus riscos políticos, a realidade que se tem de modo arbitrário. Para tais transformações, via ativismo artístico, há de se notar a intensa mobilização coletiva e multicultural performada frente a posições individuais e exclusivistas.

\section{Cartografias socioestéticas e parrésia}

Mercedes Sosa abre sua homenagem a Violeta Parra declamando o poema Defensa de Violeta Parra, de autoria de Nicanor Parra. Poderíamos, a priori, pensar que o irmão de Violeta nos dará um discurso laudatório da artista, perspectivado apenas pelos laços sanguíneos que manteria a autonomia e exclusividade social do locus familiar. No entanto, a biografia poética da artista aponta para lugares mais complexos, como podemos observar:

\section{Defensa de Violeta Parra}

Dulce vecina de la verde selva

Arpillerista azul, verde y granate

Grande enemiga de la zarzamora

Violeta Parra.

Chillaneja, locera

y costurera,

Bailarina del agua transparente

Árbol lleno de pájaros cantores

Violeta Parra.

Has recorrido toda la comarca

Desenterrando cántaros de greda

Y liberando pájaros cautivos

Entre las ramas.

parte una nueva estrella ilumina nuestro firmamento, es necesario pensar y hacer un análisis en torno a cuánto las quisimos o acogimos en el seno de nuestros pueblos" (URBIA, 2016). 
Preocupada siempre de los otros

Cuando no del sobrino

o de la tía,

Cuándo vas a acordarte de ti misma

Violeta Parra.

Tu dolor es un círculo infinito

Que no comienza ni termina nunca

Puesto que siempre has sido lo que eres

Ánfora plena.

[...]

Porque tú no te compras ni te vendes

Porque tú no te vistes de payaso

¡Porque tú los aclaras en el acto

Viola volcánica!

Tu corazón se abre cuando quiere

Tu voluntad se cierra cuando quiere

Y tu espíritu sopla cuando quiere

[...]

Cántame una canción inolvidable

Una canción que no termine nunca

Una canción no más

una canción

Es lo que pido.

Qué te cuesta mujer árbol florido

Álzate en cuerpo y alma del sepulcro

Y haz estallar las piedras con tu voz

Violeta Parra (SOSA, 1971).

Nicanor Parra realmente nos dá um quadro poético da irmã ativista. Conta-nos sobre seus labores artesanais em várias modalidades artísticas, a singularidade de sua delicadeza para a produção musical multicultural, a preocupação notória quanto aos membros de sua família, entre outras 
posturas que configuram seu campo existencial pessoal. Porém, tal descrição de vida também abrange, e esse parece ser seu ponto principal, as relações que Violeta Parra constrói com o entorno social no qual está inserida. Nesse contexto mais complexo e heterogêneo, percebemos a postura da artista que se move em constantes ativismos sociais em prol dos estratos sociais que padecem de variadas injustiças politicas.

A artista ativista acorda de si mesma e começa a enxergar as vidas que perfazem sua rede existencial. Sua mobilidade atinge lugares, cotidianos e vivências que vão bem além de seu campo individual. Seu projeto estético amplia-se pelas perspectivas de variadas etnias e culturas presentes tanto na sociedade chilena, quanto nos espaços mais amplos que envolvem os vizinhos latinoamericanos.

Claúdia Zalaquett nos informa sobre esse engajamento cultural e político:

Violeta era politicamente engajada, se preocupava com a situação do país e principalmente com o povo do campo chileno, sua raiz. Com isso, em 1952, a cantora iniciou uma intensa pesquisa e investigação sobre a música folclórica chilena, com o objetivo de resgatar canções antigas que estavam esquecidas, registrá-las em papel, e posteriormente apresentá-las para o resto do mundo. Viajou por diversas cidades à procura de gente que pudesse ajudá-la nesse processo de busca, e fez novas composições musicais, seguindo os formatos tradicionais do folclore chileno. Violeta tinha a sensibilidade de poeta para escrever canções. Algumas de suas letras retratavam questões politicas e serviam como uma forma de protesto. Outras, não menos importantes, delineavam os sentimentos humanos mais profundos.

Foi então convidada para se apresentar em escolas e universidades do Chile, divulgando suas pesquisas sobre a cultura popular, além de comandar programas de rádio que falavam sobre o assunto. Viajou para Europa, participou de festivais e propagou sua arte em diversos paises como Polônia, França e Suíça.

Cheia de aptidões, a artista também se revelou um grande talento nas artes plásticas. Não é para menos que, em 1964, 
suas obras foram apresentadas no Museu do Louvre, sendo a primeira exposição de uma artista latino-americana no local. No ano seguinte, em Santiago, Violeta fundou um centro cultural chamado "La Carpa de la Reina", onde aconteciam encontros regados a música, dança, vinho e boa comida (ZALAQUETT, 2016).

O notório conjunto de aptidões artísticas de Violeta Parra une-se então as suas aspirações por equidade política coletiva. Por mais que tenha articulado contextos de equilibração para seus familiares, seu alvo de atuação objetiva questionar as situações de autoritarismos políticos e injustiças sociais que tomavam corpo tanto do Chile quanto em vários outros países vizinhos.

O resgate de produções artísticas folclóricas coletivizadas é, pois, envolto conscientemente em suas posturas de protestos. Essas posturas exigiram que seu olhar e suas ações fossem ampliadas para a percepção de espaços mais amplos como seriam aqueles dos povos americanos. Vejamos essa amplitude maior:

\section{Los pueblos americanos}

Mi vida, los pueblos americanos, mi vida, se sienten acongojados, Mi vida, porque los gobernadores, mi vida, los tienen tan separados.

Cuándo será ese cuando, señor fiscal, que la América sea sólo un pilar.

Sólo un pilar, ay sí, y una bandera, que terminen los líos en las fronteras.

Por un puñao de tierra no quiero guerra (SOSA, 1971). 
Divulga-se, dessa forma, e se pretende consolidar a ideia de certo pan-americanismo que seria moldado pelas questões das injustiças sociais e enfrentamentos a governos totalitários. Há, então, a necessidade de se fazer frente a projetos sociopolíticos de "gobernadores" e "señor fiscal" que criam fronteiras e impedimentos para uma efetiva cooperação na produção e distribuição de capitais de diversas naturezas, que fossem capazes de produzir a equidade social. Dessa forma, o cancioneiro chileno, também performado pela voz musical argentina, conclama, de modo socioestético, os povos americanos a se unirem em uma causa comum que não aceita o limite das fronteiras geopolíticas, montadas há séculos por povos colonizadores, que ainda hoje fomentam sua separação arbitrária.

Nesse contexto, há de preparar para dizer tudo o que deve ser dito sobre o socius opressor, excludente e que funciona em sua potência devastadora sobre várias sociedades americanas, frutos dos longos e sistemáticos processos de expropriação e dominação colonialista e póscolonialista. A atitude revolucionária do ter de dizer a verdade inteira sobre tal contexto, lembra-nos das reflexões que Michel Foucault perfaz sobre o fenômeno discursivo da parresía, tanto na cultura do mundo grego antigo, quanto em suas reverberações acionais de nossa contemporaneidade. Para esse pensador ativista, nossas sociedades criam dispositivos de produção de saberes, de poderes e de construções das subjetividades possíveis. No cuidado e no conhecimento de si, estão embutidos de modo reflexivo o cuidado e o conhecimento dos outros. Nessas tecnologias de produção de subjetivações pessoais e coletivas, a prática da parresía permitiria construções intra e interpessoais nos quais predomina a preocupação em se objetivar verdades, ditas de modo franco e corajoso, que asseguram certa ordem desejada pela coletividade.

Para Foucault, a parresía

é o "dizer tudo", mas na verdade ela é traduzida, com muito mais frequência, por fala franca, liberdade de palavra, etc. Essa noção de parresía, que era importante nas práticas da direção de consciência, era, como vocês se lembram, uma noção rica, ambígua, difícil, na medida em que, em particular, designava uma virtude, uma qualidade (há pessoas que têm a parresía e outras que não têm a parresía); é um dever também (é preciso, efetivamente, sobretudo em alguns casos e situações, poder dar prova de parresía); e 
enfim é uma técnica, é um procedimento: há pessoas que sabem se servir da parresía e outras que não sabem se servir da parresía. E essa virtude, esse dever, essa técnica devem caracterizar, entre outras coisas e antes de mais nada, o homem que tem o encargo de quê? Pois bem, de dirigir os outros, em particular de dirigir os outros em seu esforço, em sua tentativa de constituir uma relação consigo mesmos que seja uma relação adequada. Em outras palavras, a parresía é uma virtude, dever e técnica que devemos encontrar naquele que dirige a consciência dos outros e os ajuda a constituir sua relação consigo (FOUCAULT, 2010, p. 42-43).

Um jogo feito no campo da luta de interesses múltiplos e contraditórios que permita um campo libertário de explicações de contextos e de judicações. Esse quadro explicita o campo da parresía como luta para se expor certas verdades e possibilidades de convencimento das pessoas que formam determinada rede de coexistência. Sabemos que tal estratégia discursiva supõe riscos politicos quando a plateia à qual o sujeito se dirige não admite o conjunto de valores e crenças veiculado. Mesmo assim, a voz que se insurge contra poderes tirânicos, não se exime de insuflar franqueza e objetividade em sua exposição por via dos variados dispositivos discursivos que é capaz de usar.

O cancioneiro de Violeta Parra, no recorte que aqui fazemos, pretende "dizer tudo" sobre os povos americanos que a artista ativista julga injustiçados. Sua ação de valorizar a cultura popular, alijada dos cânones da suposta cultura erudita, é um dos passos mais firmes e corajosos de sua posição revolucionária. No entanto, seu campo de atuação não se restringe a esses saberes que os dispositivos institucionais consideram assistemáticos, por serem predominantemente de fonte popular. Ela também busca o dialogismo com os lugares e sujeitos dos saberes legitimados pelo status quo. Percebemos isso quando a artista se dirige aos estudantes, na seguinte canção:

\section{Me Gustan Los Estudiantes}

Que vivan los estudiantes

Jardin de nuestra alegría

Son aves que no se asustan

De animal ni policía 
Y no le asustan las balas

$\mathrm{Ni}$ el ladrar de la jauría

Caramba y zamba la cosa

¡Qué viva la astronomía!

Me gustan los estudiantes

Que rugen como los vientos

Cuando les meten al oído

Sotanas y regimientos

Pajarillos libertarios

Igual que los elementos

Caramba y zamba la cosa

Qué viva lo experimento

Me gustan los estudiantes

Porque levantan el pecho

Cuando les dicen harina

Sabiéndose que es afrecho

Y no hacen el sordomudo

Cuando se presente el hecho

Caramba y zamba la cosa

¡El código del derecho!

Me gustan los estudiantes

Porque son la levadura

Del pan que saldrá del horno

Con toda su sabrosura

Para la boca del pobre

Que come con amargura

Caramba y zamba la cosa

¡Viva la literatura!

Me gustan los estudiantes

Que marchan sobre las ruinas

Con las banderas en alto

Pa? toda la estudiantina

Son químicos y doctores

Cirujanos y dentistas 
Caramba y zamba la cosa

¡Vivan los especialistas!

Me gustan los estudiantes

Que con muy clara elocuencia

A la bolsa negra sacra

Le bajó las indulgencias

Porque, hasta cuándo nos dura

Señores, la penitencia

Caramba y zamba la cosa

Qué viva toda la ciencia!

Caramba y zamba la cosa

¡Qué viva toda la ciencia! (SOSA, 1971)

Conclama-se as novas gerações, nas figuras dos jovens estudantes, para descolamentos psicossociais tidos como necessários. Necessários para o conhecimento das realidades heterogêneas que perfazem o tecido social que é descrito por Violeta Parra em seu revolucionário resgate multicultural. Nessa canção, observamos sua crença nessa nova juventude que será capaz de sair de seus lugares apaziguados, dentro dos muros das escolas, para conhecer as realidades do povo humilde que, de modo usual, não é sequer representado nos livros didáticos. Tais estudantes podem se transformar no fermento que produzirá uma nova sociedade. Do saber formal, por vezes artificioso e alheio à realidade ampliada, haverá de brotar condições ativistas preocupadas, por exemplo, com a exclusão dos mais pobres, com o que eles comem, em como eles vivem em seus cotidianos miseráveis.

Pretende-se assim discutir, de modo objetivo e franco, uma questão premente que é a exclusão de vários segmentos sociais nos contextos americanos. A estratégia da parresía visa aqui, pois, a derrubada dos muros de um sistema escolar alienado e alienador das gerações que, se sensibilizadas a contento, serão capazes de sair de seu círculo institucional conservador.

\section{Do cancioneiro às razões práticas}

A expressão estética, exposta nessa homenagem que Mercedes Sosa faz ao cancioneiro de Violeta Parra, destaca-nos o sentido que se quer imprimir a arte da poesia e da música populares. Não há de se enfatizar 
nessas práticas artísticas o que seria seu caráter de massificação. Características formais como escolha de instrumentos musicais, de ritmos, de melodias, de tropos literários, não predominam sobre as temáticas de cunho político-sociais. Ao contrário, pretende-se atingir aquele delicado plano de natural ontologia entre fundo e forma.

Esse objetivo estético revolucionário pretende convencer, na perspectiva do discurso franco e propedêutico da parresía, as relações históricas entre produtos multiculturais e posicionamentos políticos de intervenção social. No caso específico do campo poético e musical, lembramo-nos também das reflexões feitas por Theodor Adorno sobre a função e valoração do fenômeno artístico em sua frente de massificação e naquela de produção e distribuição crítica popular:

A modificação da função da música atinge os próprios fundamentos da relação entre arte e sociedade. Quanto mais inexoravelmente o princípio do valor de troca subtrai aos homens os valores de uso, tanto mais impenetravelmente se mascara o próprio valor de troca como objeto de prazer. Tem se perguntado qual seria o fator que ainda mantém coesa a sociedade da mercadoria (e consumo). Para elucidar tal fato pode contribuir aquela transferência do valor de uso dos bens de consumo para o seu valor de troca dentro de uma constituição global, na qual, finalmente, todo prazer que se emancipa do valor de troca assume traços subversivos. O aparecimento do valor de troca nas mercadorias assumiu uma função específica de coesão (ADORNO, 1996, p. 78).

O prazer da recepção e do dialogismo artístico faz-se, portanto, na relação que envolve o valor de uso e não apenas no contexto fetichista articulado pelo valor arbitrário de troca. A produção artística pode, então, ser questionada em sua performance de bem de consumo alienado e alienante em relação aos seus valores expressos e transmitidos. A coesão do valor de troca, no caso dos cancioneiros populares, aqui representado pelas canções de Violeta Parra, é desmontada de modo ativo e crítico para que possamos compreender, também de modo estético, realidades das quais, por vezes, não tínhamos a visão pragmática.

Desse modo, forma e conteúdo, em sua conjunção intrínseca, apontam-nos para contextos nos quais o cancioneiro possui estreito laços 
com cotidianos sociais a serem desvendados e transformados, como acompanhamos na canção:

\section{Los hambrientos piden pan (O La carta)}

Me mandaron una carta, por el correo temprano, en esa carta me dicen que cayó preso mi hermano. Y sin compasión con grillos por las calles lo arrastraron. Sí...

La carta dice el motivo, que ha cometido Roberto, haber apoyado el paro que ya se había resuelto. $\mathrm{Si}$ acaso esto es un motivo preso voy también sargento. Sí...

Yo que me encuentro tan lejos, esperando una noticia, me viene a decir en la carta que en mi patria no hay justicia. Los hambrientos piden pan, los molesta la milicia.

Sí...

Habrase visto insolencia, barbarie y alevosía, de presentar el trabuco y matar a sangre fría. Hay quien defensa no tiene con las dos manos vacías. Sí...

La carta que me mandaron me pide contestación, yo pido que se propale 
por toda la población.

Que el león es un sanguinario

en toda generación.

Sí...

Por suerte tengo guitarra

y también tengo mi voz, también tengo siete hermanos

fuera del que se engrilló.

Todos revolucionarios con el favor de mi Dios.

Sí... Sí (SOSA, 1971)

Tanto a letra da canção, de Violeta Parra, quanto a interpretação musical rápida, encorpada e com timbres trágicos impostos por Mercedes Sosa, colocam-nos no palco de um acontecimento factual, mergulhado na estética do campo bastante verossímil de relações políticas autoritárias vivenciadas pela sociedade chilena, bem como pelos demais povos americanos. À situação de autoritarismo político, que precederá regimes ditatoriais pragmáticos na segunda metade do século passado, insurge-se a voz do irmão da artista ativista. A carta recebida configura o fato autoritário baseado no veredito feito ao arrepio das leis, e chama a irmã a um posicionamento de luta.

Diante da injustiça natural do sistema político ditatorial, o eu lírico da canção faz uso de sua discursividade franca, apesar de saber dos riscos que tal parresía poderá lhe trazer. Seu enfrentamento dá-se através de sua arte de cancioneira, com o uso de sua guitarra, de sua voz, e, sobretudo, da conclamações das demais vozes que haverão de se levantar contra o abuso político da perseguição aos revolucionários; sejam os revolucionários de sua família ou aqueles da família mais ampla dos variados povos americanos, que passam por situação semelhante

"[...] en mi patria no hay justicia" é uma constatação de que o corpo da canção, em sua dimensão intrínseca de forma e conteúdo, consegue se desvencilhar da massificação da arte poética e musical, na qual tantos produtos culturais contemporâneos são instados a se localizarem. Os objetos que funcionam como fonte do prazer estético são ressignificados e passam a funcionar como dispositivos de conscientização e de mobilização para efetivas ações críticas de enfrentamentos e de transformações sociais. 
Nesse âmbito socioestético, as razões para ações práticas, mais que individuais, quando mencionamos o fato da presença do eu lírico na canção, encaminha-se para o fenômeno da ação coletiva, insuflada pela coragem de demonstrar o socius tensionado por interesses contraditórios.

\section{As graças da vida coletiva}

Violeta Parra, quando acompanhamos sua biografia socioestética, passou por cartografias de ativismo que lhe ocasionaram variados sofrimentos pessoais. Como mencionamos anteriormente, sua vida pessoal e familiar esteve frequentemente envolta por condições de variadas exclusões. Mesmo com esse quadro adverso, teve disposição e condições de luta que aglutinaram o seu núcleo familiar.

Situação semelhante pode ser percebida no contexto que envolve as condições pessoais de Mercedes Sosa. Questões familiares frequentemente influenciadas por fragilidades financeira e baixa densidade na participação dos privilégios sociais de suas épocas, davam a tônica pelas quais poderíamos enfatizar as condições individuais dessas artistas ativistas. No entanto, suas razões práticas direcionaram-nas para atuações em campos maiores que os das individualidades singulares. Suas atuações ocorrem em pleno tecido social coletivizado e solidário.

O poder de inclusão pessoal em uma rede ampla e heterogênea nos remete à dinâmica da diáspora espacial e subjetiva na qual tais figuras são lançadas. Tanto Violeta Parra quanto Mercedes Sosa são marcadas por suas mobilidades forçadas ou espontâneas. Ambas saem de suas regiões de origem e ganham variadas outras geopoliticas nas quais vivenciam suas crenças artísticas e políticas. Por diáspora, compreendemos aqui o que nos explica Stuart Hall:

Na situação da diáspora, as identidades se tornam múltiplas. Junto com os elos que as ligam a uma ilha de origem especifica, há outras forças centrípetas. Esta é a sensação familiar e profundamente moderna de deslocamento, a qual - parece cada vez mais - não precisamos viajar muito longe para experimentar. Talvez todos nos sejamos, nos tempos modernos - após a Queda, digamos - o que o filósofo Heidegger chamou de unheimlicheit- literalmente, "não estamos em casa" (HALL, 2003, p. 27). 
Identidades múltiplas são daqueles produtos culturais produzidos pela diáspora, tanto política quanto identitária. No âmbito dos deslocamentos forçados, observamos como se pode produzir a sensação do "não estarmos em casa"; ou então, de que nossa casa possui vastidão mais ampla que o convencional construto que pensamos ser nosso lar singularizado.

O deslocamento ocasionado pela condição diaspórica pode ser percebido na já clássica canção Gracias a la vida, que também nós, brasileiros, aprendemos a cantar desde os anos 70, quando vivíamos tempos políticos ditatoriais, tendo nosso direito de expressão e de mobilidade violentamente desrespeitado. Eis a canção:

\section{Gracias A La Vida}

Gracias a la vida que me ha dado tanto

Me dio dos luceros que cuando los abro

Perfecto distingo lo negro del blanco

Y en el alto cielo su fondo estrellado

$\mathrm{Y}$ en las multitudes el hombre que yo amo

Gracias a la vida que me ha dado tanto

Me ha dado el oído que en todo su ancho

Graba noche y día grillos y canarios

Martillos, turbinas, ladridos, chubascos

Y la voz tan tierna de mi bien amado

Gracias a la vida que me ha dado tanto

Me ha dado el sonido y el abecedario

Con él, las palabras que pienso y declaro

Madre, amigo, hermano

Y luz alumbrando la ruta del alma del que estoy amando

Gracias a la vida que me ha dado tanto

Me ha dado la marcha de mis pies cansados

Con ellos anduve ciudades y charcos

Playas y desiertos, montañas y llanos

Y la casa tuya, tu calle y tu patio 
Gracias a la vida que me ha dado tanto

Me dio el corazón que agita su marco

Cuando miro el fruto del cerebro humano

Cuando miro el bueno tan lejos del malo

Cuando miro el fondo de tus ojos claros

Gracias a la vida que me ha dado tanto

Me ha dado la risa y me ha dado el llanto

Así yo distingo dicha de quebranto

Los dos materiales que forman mi canto

Y el canto de ustedes que es el mismo canto

Y el canto de todos que es mi propio canto

Gracias a la vida, gracias a la vida (SOSA, 1971)

Em tempos sombrios de gestação e de consolidação sistêmica de vários governos ditatoriais entre os povos americanos, Violeta Parra produz um hino de gratidão à vida que lhe permite ativar ações de protestos e de reconstrução de ordens sociais injustas e exclusivistas. A canção nos oferece uma espécie de gradação no campo da individualidade do eu lírico. De início, vemos os agradecimentos à eficiência do aparelho perceptivo singularizado. Em seguida, seu núcleo familiar e afetivo é elencado. A natureza é agraciada na ternura anímica. Por fim, uma rede maior de pessoas é colocada no campo dos agradecimentos. Convive-se em coexistência com seres e fenômenos variados e as graças que se oferece à vida contempla essa complexidade vivencial. A parresía de protesto funciona como um dos mecanismos de mobilização coletiva para as ações práticas.

O cantar, mais que prática individual, torna-se uma estratégia negociada de luta contra os autoritarismos políticos de sociedades movidas por regras de injustiças e de exclusão social. Em tonalidade semelhante, também temos outra canção, fora de nosso recorte em questão, que perfaz percurso semelhante, que é Solo le pido a Dios, de autoria do argentino León Gieco, também interpretada e difundida por Mercedes Sosa:

\section{Solo le pido a Dios}

Sólo le pido a Dios

Que el dolor no me sea indiferente

Que la reseca muerte no me encuentre 
Vacía y sola sin haber hecho lo suficiente

Sólo le pido a Dios

Que lo injusto no me sea indiferente

Que no me abofeteen la otra mejilla

Después que una garra me arañó esta suerte

Sólo le pido a Dios

Que la guerra no me sea indiferente

Es un monstruo grande y pisa fuerte

Toda la pobre inocencia de la gente

Es un monstruo grande y pisa fuerte

Toda la pobre inocencia de la gente

Sólo le pido a Dios

Que el engaño no me sea indiferente

Si un traidor puede más que unos cuantos

Que esos cuantos no lo olviden fácilmente

Sólo le pido a Dios

Que el futuro no me sea indiferente

Desahuciado está el que tiene que marchar

A vivir una cultura diferente

Sólo le pido a Dios

Que la guerra no me sea indiferente

Es un monstruo grande y pisa fuerte

Toda la pobre inocencia de la gente

Es un monstruo grande y pisa fuerte

Toda la pobre inocencia de la gente (SOSA; GIECO; NASCIMENTO, 1986)

De extração aparentemente personalista, um eu lírico expõe afetos e sentidos, assemelhando a canção à Gracias a la vida, pelo aspecto de seu caráter dialógico de combate. Os versos "Que el dolor/ no me sea indiferente/ Que la reseca muerte no me encuentre/Vacía y sola sin haber hecho lo suficiente" nos alertam para supostos perigos, tanto de uma vida sem ação de combates, quanto à guerra assumida de modo solitário. 
A pobre inocência das gentes há de ser defendida e sanada por esforços solidários e cooperativos. $\mathrm{O}$ altruísmo personalizado não é prática suficientemente capaz de reverter o quadro da falta de equidade sociopolitica. $\mathrm{O}$ artista, pois, mais que ir aonde o povo humilde está, sentese historicamente membro ativo e ativador desse povo. Ou seja, do procedimento individual, vai-se ao procedimento coletivo, modificado por intervenções estéticas e politizadas.

Tais cancioneiros perfazem, pois, o caráter daquela educação cultural que objetiva a mobilidade, tanto geográfica quanto multicultural, da qual, por exemplo, o antropólogo do cotidiano, Marc Augé, ensina-nos:

A educação deve inicialmente ensinar a todos a mudar o tempo para sair do eterno presente fixado pelas imagens em círculo, e fazer mudar o espaço, isto é, a mudar no espaço, a sempre ir ver mais de perto e a não se nutrir exclusivamente de imagens e mensagens. E preciso aprender a sair de si, a sair de seu entorno, a compreender que é a exigência do universal que relativiza as culturas e não o inverso. E preciso sair do cerco culturalista e promover o indivíduo transcultural, aquele que, adquirindo o interesse por todas as culturas do mundo, não se aliena em relação a nenhuma delas.

E preciso aprender a sair de si, a sair de seu entorno, a compreender que é a exigência do universal que relativiza as culturas e não o inverso. É preciso sair do cerco culturalista e promover o indivíduo transcultural, aquele que, adquirindo o interesse por todas as culturas do mundo, não se aliena em relação a nenhuma delas (AUGÉ, 2010, p. 109).

O sair de nós mesmos, pela mobilidade geopolítica e cultural, para a percepção de que a outridade excluída faz parte intrínseca de nós mesmos, é um dos móveis desse cancioneiro de Violeta Parra, bem como de sua divulgação e consolidação por parte de Mercedes Sosa. Há, então, uma dialética movida pela convicção de que o indivíduo transcultural seja capaz de colocar-se entre o que lhe seria particular e o que lhe seria, em um primeiro tempo, alheio. As graças que damos à vida e os pedidos que fazemos aos deuses estão alicerçados nessa dinâmica de prazer estético e de educação pelo discurso franco e veiculador de interesses coletivos inclusivos. 


\section{Conclusão}

Objetivamos, nesse breve estudo, acompanhar parte do cancioneiro de Violeta Parra, homenageado, divulgado e consolidado por Mercedes Sosa. Ambas fizeram parte de movimentos artísticos programáticos. Aqui em especial os movimentos poéticos e musicais, que se preocupavam em expressar temáticas sociopoliticas pertinentes a exclusões de várias esferas dos povos americanos.

Diante dos governos ditatoriais que se gestavam e se consolidavam à época, segunda metade do séc. vinte, as duas artistas ativistas tiveram a coragem suficiente do uso discurso da parresía, colocando-se em relevantes riscos, do que seriam suas integridades individuais. No entanto, mais que ambicionarem equilibração egóica, Violeta Parra e Mercedes Sosa deslocaram suas posições de luta do campo individual para o campo coletivo em franca relação dialógica.

Esse deslocamento psicossocial insere-se no plano da mobilidade produzida pela dialética entre o próprio e o alheio, na qual a perspectiva multicultural é valorizada como fonte de inspiração para posições de combate. Assim, construtos culturais canônicos são influenciados pela produção cultural de populações colocadas a margens de condições de bemestar excludentes. A cultura popular, semelhante àquela literatura menor ${ }^{95}$, faz-se ouvir, mobilizando grandes contingentes transnacionais em prol de objetivos comuns. Do Chile para a Argentina, também se vai para os

\footnotetext{
${ }^{95}$ Por literatura menor, aqui tomado em sentido ampliado ao campos das artes em geral, acompanhamos Gilles Deleuze e Félix Guattari refletindo sobre a obra de Franz Kafka, no contexto de autoritarismo politico europeu. Para ele: "Uma literatura menor não é a de lingua menor, mas antes aquilo que uma minoria faz em uma lingua maior. No entanto, a primeira caracteristica e, de qualquer modo, que a lingua ai é modificada por um forte coeficiente de desterritorialização. [...] A segunda característica das literatura menores é que nelas tudo é politico. Nas grandes literaturas, ao contrário, o caso individual (familiar, conjugal, etc.) tende a ir ao encontro de outros casos não menos individuais, servindo o meio social como ambiente e fundo; embora nenhum desses casos edipianos seja particularmente indispensável, todos "formam um bloco" em um amplo espaço. A literatura menor é totalmente diferente: seu espaço exíguo faz com que cada caso individual seja imediatamente ligado à política. $\mathrm{O}$ caso individual se torna então mais necessário, indispensável, aumentado ao microscópio, na medida em que uma outra história se agita nele. [...] A terceira caracteristica é que tudo adquire um valor coletivo. Com efeito, precisamente porque os talentos não abundam em um literatura menor, as condição não são dados de uma enunciação individuada, que seria a de tal ou tal "mestre", e poderia ser separada da enunciação coletiva (DELEUZE; GUATTARI, 1975, p. 25).
} 
demais países americanos que forçosamente, e à custa de muitos sacrifícios, enfrentaram os sombrios tempos movidos pelo princípio da morte. A esse princípio, temos as luzes dos cancioneiros implementados por essas duas artistas ativistas.

\section{REFERÊNCIAS}

ADORNO, Theodor W. Textos Escolhidos. Tradução de Zeljko Loparic et al. São Paulo: Nova Cultural. Coleção Grandes Pensadores, 1996.

. Filosofia da nova música. Tradução de Magda França. São Paulo: Perspectiva, 1989.

AUGÉ, Marc. Por uma antropologia da mobilidade. Tradução de Bruno César Cavalcanti e Rachel Rocha de Almeida. Maceió: EDLTFAL/UNESP, 2010.

BESSA, Priscila. Andrés Wood sobre Violeta Parra: 'Ela sempre foi uma mulher suicida." In: <http://ultimosegundo.ig.com.br/cultura/cinema/2012-06-02/andreswood-sobre-violeta-parra-ela-sempre-foi-uma-mulher-suicid.html>. Acesso em 25 de maio de 2016.

BIBLIOTECA NACIONAL DO CHILE. Memória Chilena: la nueva canción chilena. In: <http://www.memoriachilena.cl/602/w3-article702.html>. Acesso em 02 de junho de 2016].

DELEUZE, Gilles; GUATTARI, Félix. Kafka: por uma literatura menor. Tradução de Júlio Castañon Guimarães. Rio de Janeiro: Imago, 1975.

FOUCAULT, Michel. A coragem da verdade. O governo de si e dos outros II. Curso no Collège de France (1983-1984). Edição estabelecida por Frédéric Gros, sob a direção de François Ewald e Alessandro Fontana. Tradução de Eduardo Brandão. São Paulo: Editora Martins Fontes, 2011.

. O governo de si e dos outros: curso no College de France (1982-1983).

Tradução de Eduardo Brandão. São Paulo: Editora Martins Fontes, 2010. 
A hermenêutica do sujeito: curso no Collège de France (1981-1982). Tradução de Márcio Alves da Fonseca e Salma Tannus Muchail. São Paulo: Martins Fontes, 2006.

FUNDAC̣ÃO MUSEU VIOLETA PARRA. Violeta Parra. In: $<$ http://docplayer.com.br/15116085-Fundacao-museu-violetaparra.html>. Acesso em 24 de maio de 2016.

HALL, Stuart. Da Diáspora: identidades e mediações culturais. Organização de Liv Sovik e Tradução de Adelaine La Guardia Resende. Belo Horizonte: Editora UFMG; Brasília: Representação da Unesco no Brasil, 2003.

MEMÓRIAS DA DITADURA. Violeta Parra. In: <http://memoriasdaditadura.org.br/artistas/violeta-parra/>. Acesso em 05 de junho de 2016.

MODELLI, Laís. Mercedes Sosa: a voz da américa latina. In: <http://www.carosamigos.com.br/index.php/cultura/5448-mercedessosa-a-voz-da-america-latina>. Acesso em 29 de maio de 2016.

P.S.T.U. Violeta Parra: filme traz vida e obra de cantor rebelde que transcende gerações. Disponivel online em <http://www.pstu.org.br/conteudo/violeta-parra-filme-traz-vida-e-obra-decantora-rebelde-que-transcende-gera\%C3\%A7\%C3\%B5es>. Acesso em 03 de junho de 2016.

RODRIGUES, Osvaldo Gitano. La peña de los Parra. In: <http://www.abacq.net/imagineria/disc003.htm>. Acesso em 12 de junho de 2016.

ROLLE, Claudio. La nueva canción chilena. El proyecto cultural popular y la campaña presidencial y gobierno de salvador allende. In: $<$ http://pensamientocritico.imd.cl/index.php?option=com_content\&vie $\mathrm{w}=$ article\& id=80:la-nueva-cancion-chilena-el-proyecto-cultural-popular-y-lacampana-presidencial-y-gobierno-de-salvador-allende\& catid=36:no2\&Itemid=61>. Acesso em 05 de junho de 2016. 
SOSA, Mercedes. Homenaje a Violeta Parra. Argentina: Universal Music. 1971.

SOSA, Mercedes Sosa; GIECO, León; NASCIMENTO, Milton. Corazón Americano. Buenos Aires: Polygram, 1986.

URTUBIA, Cristian. Llamémosle casualidad. In: <http://www.educarchile.cl/ech/pro/app/detalle?id=198904>. Acesso em 04 de junho de 2016.

VILA, Rodrigo H. Mercedes Sosa: la voz de latinoamerica. Argentina. Documentário musical. 1h50m, 2013.

VIOlETA SE FUE A LOS CIELOS. Direção de Andrés Wood, Chile. Wood Producciones S.A / Maiz Producciones S.A. 1h10m, 2011.

ZALAQUETT. Violeta Parra, a chilena que conquistou o mundo. In: <http://lounge.obviousmag.org/inspirese/2015/06/violeta-parra-achilena-que-conquistou-o-mundo.html>. Acesso em 02 de junho de 2016.

Recebido em: 15/06/2016

Aceito em: 25/07/2016 